\title{
EVALUATION OF PHYTOCHEMICALS AND SYNERGISTIC INTERACTION BETWEEN PLANT EXTRACTS AND ANTIBIOTICS FOR EFFLUX PUMP INHIBITORY ACTIVITY AGAINST SALMONELLA ENTERICA SEROVAR TYPHIMURIUM STRAINS
}

\author{
JYOTI MEHTA*, SAVITA JANDAIK, URMILA \\ Department of Microbiology, Shoolini University of Biotechnology and Management Sciences, Bajhol 173229, Solan, Himachal Pradesh \\ Email: yjjyoti@gmail.com
}

Received: 12 Jul 2016 Revised and Accepted: 12 Aug 2016

\begin{abstract}
Objective: Traditional antibiotics are increasingly suffering from the emergence of efflux related multidrug resistance (MDR) amongst pathogenic bacteria that led to novel approaches to control microbial infections being investigated as potential alternative treatments. Synergism between natural sources and antibiotics has received much attention and efforts have been put in to identify compounds that can act as efflux pump inhibitors.

Methods: Methanol and ethyl acetate extracts of important medicinal plant species widely used in traditional remedies for various ailments were screened for their synergism with ciprofloxacin and tetracycline antibiotics using the agar well diffusion method. Phytochemical analysis was also done by standard methods. In addition, to evaluate the potential of synergistic extracts as efflux pump inhibitors against Salmonella enterica serovar Typhimurium (S. Typhimurium) strains, including wild-type (NKS70), overexpressed AcrAB (NKS773) as well as against knockout TolC (NKS174), berberine uptake and ethidium bromide inhibition assays were done.

Results: In vitro synergistic activity were confirmed for methanolic extracts of all five plants, namely, Allium sativum (Amaryllidaceae), Syzygium aromaticum (Myrtaceae), Berberis aristata (Berberidaceae), Rhus cotinus (Anacardiaceae), and Phyllanthus emblica (Phyllanthaceae). Agar well diffusion method confirmed the greatest synergistic activity of $P$. emblica with used antibiotics. The phytochemical analysis of medicinal plants showed that the terpenoids and reducing sugar were found to be present in all synergistic extracts. Phytochemicals have great potential as antimicrobial agents. Further efflux inhibition assays confirmed maximum efflux pump inhibition through Phyllanthus emblica extract against $S$. Typhimurium when extracted with methanol solvent.
\end{abstract}

Conclusion: It is hypothesized that phyto compounds present in these plants might be following the same mechanism of action responsible for synergistic interaction as well as efflux inhibition. These data provide bioactive compounds for possible clinical utility as efflux inhibitors.

Keywords: Antibiotics, Efflux pump inhibition, Medicinal plants, S. Typhimurium, Synergistic activity

(C) 2016 The Authors. Published by Innovare Academic Sciences Pvt Ltd. This is an open access article under the CC BY license (http://creativecommons. org/licenses/by/4. 0/)

DOI: http://dx.doi.org/10.22159/ijpps.2016v8i10.14062

\section{INTRODUCTION}

Salmonella enterica serovar Typhimurium (S. Typhimurium) is a facultative anaerobic Gram-negative foodborne pathogen under the family Enterobacteriaceae. They cause various diseases in humans and animals, from gastroenteritis to bacteremia and typhoid fever [1]. Multidrug-resistant bacteria resist a broad range of antimicrobials thereby reducing the treatment options and hence increasing the mortality rate day by day in developing countries where the use of antibiotics is high. This problem of antimicrobial resistance is of great concern. In the past few years, rapid and widespread emergence of resistance to newly introduced antimicrobial agents indicates that even new families of antimicrobial agents will have a short life expectancy [2]. One way of prolonging antibiotic efficiency or potentiating the activity of antibiotics against drug-resistant pathogens is by blocking drug efflux pumps with efflux pump inhibitors (EPIs), attractive compounds known to reverse multidrug resistance and prevent the development of resistance in clinically relevant bacterial pathogens [3-6]. Therefore, researchers are increasingly making efforts that lead to the development of better drugs against MDR microbe strains with the use of herbal products [7]. Tyagi et al. [8] reviewed a number of herbal plants that has been used as a drug in the form of crude extracts and extensively used for their antimicrobial possessions. Different plant extracts exhibit variation in their activity against uropathogenic E. coli, Enteropathogenic E. coli, Enterotoxigenic E. coli, S. Typhimurium, K. pneumoniae and P. aureginosa [9].

Natural products play a major role in drug discovery by providing bioactive scaffolds with activity against a variety of targets in infections. Efflux pump inhibitors (EPIs) isolated from natural sources are the best strategy of efflux system inhibition, which has emerged from the last few decades. Reports for novel and already known natural chemical entities which are active against all of the major microbial efflux systems have populated the chemical space as well as the literature $[10,11]$. Medicinal plants contain some organic compounds such as tannins, alkaloids, flavonoids, carbohydrates, terpenoids and steroids, which produces definite physiological action on humans $[12,13]$ and in vitro found to have antimicrobial properties [14]. There is a vast array of medicinal plants used singly or in combination with antibiotics that confer synergistic effects in the treatment of various ailments. The combination of an antibiotic with an efflux pump inhibitor (EPI) would be expected to reestablish susceptibility of the bacteria to antibiotics that at present cannot be used any longer. The mode of action of combination therapy significantly differs from that of the same drugs acting individually. Therefore the selection of an appropriate combination is crucial and essential which requires understanding the potential interaction between the plant extracts and antimicrobial agents. Antimicrobial agents are exported out of the bacterial cell through efflux pumps that serve to protect it from building up to toxic levels and led to the development of resistance to antimicrobials [15-19].

In Enterobacteriaceae family, overproduction of the AcrAB-TolC efflux pumps confers clinically relevant resistance to many antimicrobial agents, including ciprofloxacin and tigecycline [20] and are associated with innate multidrug resistance resulting in major clinical problem, so there is a need to understand their physiology to reveal their interesting perspectives uses in combination therapy along with existing antibiotics that lead to the development of inhibitors. 
Identification of new efflux pump inhibitors (EPIs) is expected to hasten the development of effective adjuvant therapies to existing antibiotics. The EPIs can effectively increase the intracellular concentration of the drug to the level essential for its activity and hence reduce the minimal inhibitory concentration required for the antibiotic to kill the resistant organisms. Plants have evolved to effectively fight off infections by producing an array of special chemicals. We were specifically interested in identifying EPIs from plant sources. Therefore, in the present study, the plant extracts that have been shown to act synergistically with antibiotics such as ciprofloxacin and tetracycline were analyzed for their phytochemicals that have a major role in the identification and development of effective efflux pump inhibitors against Salmonella Typhimurium.

\section{MATERIALS AND METHODS}

\section{Selection of plant material}

Fresh leaves of Berberis aristata (Berber dance) and Rhus cotinus (Anacardiaceae), Fruits of Phyllanthus emblica (Phyllanthaceae), flower bud of Syzygium aromaticum (Myrtaceae) and bulb of Allium sativum (Amaryllidaceae) selected on the basis of traditional applications and pharmacological reports were collected from surroundings and local market into plastic zip lock bags with appropriate labelling and got identified from Botany department of Shoolini University of biotechnology and Management Sciences, Bajhol, India. Voucher specimens have been submitted to the herbarium of the University (mentioned in tables).

\section{Preparation of plant extracts}

The collected samples were carefully washed under running tap water to remove debris and dust particles, followed by washing with $0.1 \%$ mercuric chloride to remove the contamination and after that washed with distilled water and shade dried for 4-5 d. The dried plant materials were ground to powder and stored in airtight containers. 70\% methanol and ethyl acetate were used as extraction solvents. $10 \mathrm{~g}$ of powdered sample was soaked in a conical flask containing $100 \mathrm{ml}$ of solvents with occasional shaking followed by keeping all the flasks on a rotary shaker at $200 \mathrm{rpm}$ and filtered through a sterilized Whatman No. 1 filter paper after $48 \mathrm{~h}$. The plant residue was re-extracted with the addition of solvents, and after 24 $\mathrm{h}$, it was filtered again. Combined filtrates were concentrated to dryness at $40{ }^{\circ} \mathrm{C}$ on a rotary evaporator. The dried extract, thus, obtained was sterilized by overnight UV-irradiation, checked for sterility on nutrient agar plates and stored at $4{ }^{\circ} \mathrm{C}$ in a refrigerator for further use [21]. The dried extracts were reconstituted to $5 \%$ in Dimethyl sulphoxide (DMSO) for further use.

\section{Microbial strains and culture conditions}

Three strains of Salmonella enterica serovar Typhimurium NKS70 (wild type), NKS174 (TolC knockout) and NKS773 (AcrAB over expressive) were used as test organisms in the present study. All three strains were a generous gift given by Kunihiko Nishino, Associate professor of Osaka University (Japan). All strains were maintained in $30 \%(\mathrm{v} / \mathrm{v})$ glycerol at $-80^{\circ} \mathrm{C}$ until required. The pure bacterial cultures were maintained on bismuth sulphite agar and Luria-Bertani medium (LB media were obtained from Acumedia and Agar from Oxoid). Each bacterial culture was further maintained by subculturing on the same medium and stored at $4{ }^{\circ} \mathrm{C}$ until use. Cell growth (optical density) was assessed with a spectrophotometer at $600 \mathrm{~nm}$. Cells were used for experiments in the mid-log growth phase (optical density at $600 \mathrm{~nm}, \sim 0.4$ to 0.8 or $10^{\beta} / \mathrm{ml}$ ).

\section{Chemicals used}

Fehling solution A, Fehling solution B, hydrochloric acid ( $\mathrm{HCl})$, acetic anhydride, methanol, ethyl acetate, ethanol, sodium hydroxide $(\mathrm{NaOH})$, iodine, potassium iodide, chloroform, concentrated sulphuric acid, DMSO, and ferric chloride were obtained from SigmaAldrich Chemical Co. (India). All the chemicals and solvents used were of standard analytical grades.

\section{Antimicrobial agents and antibiotics}

Two antibiotics (tetracycline and ciprofloxacin were purchased from Himedia Laboratory, India) were evaluated for synergism with extracts of five medicinal plants. Zones of inhibition were determined in accordance with the procedures of the National Committee for Clinical Laboratory Standard [22]. Bacterial strain was considered susceptible to antibiotics if the inhibition zones were $\geq 13 \mathrm{~mm}$.

\section{Evaluation of the synergistic activity of plant extracts with antibiotics}

Synergistic activity of a plant extracts of 5 medicinal plants with two above-mentioned antibiotics were investigated using the agar well diffusion method [23]. Petri plates containing $30 \mathrm{ml}$ Mueller-Hinton agar medium were kept for solidification followed by spreading 100 $\mu \mathrm{l}\left(10^{6} \mathrm{CFU} / \mathrm{ml}\right)$ of the microorganism (24 h broth culture). Four wells of uniform diameter of $6 \mathrm{~mm}$ made after solidification, using sterile aluminum borer. Four wells ( $6 \mathrm{~mm}$ diameter) were punched in the Mueller Hinton agar and the combination of $40 \mu \mathrm{l}$ of 100 $\mathrm{mg} / \mathrm{ml}$ plant extracts and antibiotics were added in a well along with antibiotic and plant extract alone in other two wells. The negative control was DMSO. After incubation for $24 \mathrm{~h}$ at $37^{\circ} \mathrm{C}$, the plates were observed for the synergistic activity, and diameter of the zone of inhibition for each extract was measured in terms of a millimeter $(\mathrm{mm})$. The experiment was repeated in triplicate for each extract.

\section{Qualitative tests for phytochemicals}

Screening of the extracts of above five selected synergistic medicinal plants for various phytochemical constituents carried out using standard methods [24-29]

\section{Test for alkaloids (Wagner's test)}

A fraction of the extract was treated with 3-5drops of Wagner's reagent $[1.27 \mathrm{~g}$ of iodine and $2 \mathrm{~g}$ of potassium iodide in $100 \mathrm{ml}$ of water] and observed for the formation of a reddish brown precipitate (or coloration).

\section{Test for flavonoid (Alkaline reagent test)}

Treat the extract with dilute $\mathrm{NaOH}$, followed by the addition of dilute $\mathrm{HCl}$. A yellow solution with $\mathrm{NaOH}$ turns colorless with dilute $\mathrm{HCl}$.

\section{Test for saponins (Frothing test)}

Saponins were tested by dissolving one-half grams $(0.5 \mathrm{~g})$ of the crude extract in a test tube containing $3 \mathrm{ml}$ of hot distilled water and then the mixture was shaken vigorously for one minute and persistent foaming observed indicated the presence of saponins.

\section{Test for terpenoids (Salkowki's test)}

$1 \mathrm{ml}$ of chloroform was added to $2 \mathrm{ml}$ of each extract followed by a few drops of concentrated sulphuric acid. A reddish brown precipitate produced immediately indicated the presence of terpenoids.

\section{Reducing sugars (Fehling test)}

The extracts were shaken with distilled water, filtered and boiled with a few drops of Fehling's solution A and B for a few minutes. Orange/red color indicates the presence of reducing sugars.

\section{Test for phenols}

A small amount of the extract was treated with $2 \mathrm{ml}$ of ethanol and a few drops of ferric chloride solution added to it. The blue color indicates the presence of phenols.

\section{Screening of crude plant extracts for efflux pump inhibitory activity}

\section{Berberine uptake assay}

Screening of crude plant extracts for efflux pump inhibitory activity was done by berberine uptake assay [30]. Serial 2-fold dilutions of berberine and a plant extract were mixed in each well of a 96-well microtiter plate. Each row (and column) contained a fixed amount of one agent and increasing amounts of the second agent. The plate presents a pattern in which every well contain a unique combination of concentrations between the two molecules. The concentrations of berberine (row) range from 30 to $0.5 \mu \mathrm{g} / \mathrm{ml}(89-1.5 \mu \mathrm{M})$, while plant 
extracts (column) concentrations range from 15 to $0.015 \mu \mathrm{g} / \mathrm{ml}$. Berberine without plant extracts was used as negative control. CCCP was added into the culture along with berberine as a positive control. Cells were added to each well at a final concentration of $5 \times$ $10^{6} \mathrm{CFU} / \mathrm{ml}$, and plates were incubated at $37^{\circ} \mathrm{C}$ for $24 \mathrm{~h}$. Growth was assayed by absorption at $600 \mathrm{~nm}$ with a microtiter plate reader. An optical density less than 0.04 revealed no bacterial growth.

\section{Ethidium bromide efflux inhibition assay}

The ethidium bromide efflux inhibition assay was also performed for the confirmation of efflux pump inhibitory activity [31]. $175 \mu \mathrm{l}$ of bacterial inoculum were added to each well of 96 well microtiter plate. $5 \mu \mathrm{l}$ of test compound were added to columns 1-10. $20 \mu \mathrm{l}$ of $100 \mu \mathrm{M}$ EtBr were added to each well. $5 \mu \mathrm{l}$ of positive control (CCCP) was added to the eleventh column. $5 \mu \mathrm{l}$ of negative control (DMSO) without plant extract was added to column 12. Plates were immediately placed in Fluoroscan Ascent and fluorescence of the accumulated $\mathrm{EtBr}$ was measured for $30 \mathrm{~min}$ with $5 \mathrm{~min}$ of the interval at $530 \mathrm{~nm}$ excitation and $600 \mathrm{~nm}$ emission. Sterile microtiter plates were used for this assay.

\section{RESULTS}

The zone diameters were found to increase when extracts were used in combination with antibiotics. The combination was found to be more potent than either of the two. Differences in diameter of inhibition zone $\geq 4 \mathrm{~mm}$ between the combined effect of medicinal plants with ciprofloxacin and tetracycline and antibacterial activity of ciprofloxacin and tetracycline alone revealed the synergistic activity of that plant extract. Inhibition zones are represented in millimeter ( $\mathrm{mm})$.

Table 1 presents the synergistic activity of plant extracts with ciprofloxacin. Among methanolic extracts, $R$. cotinus showed a maximum zone of inhibition alone, but in combination with antibiotics, P. emblica showed maximum synergism and was found to be very effective with antibiotics. Minimum or no zone of inhibition was observed in plant extract of B. aristata. Similarly, all methanolic extracts and ethyl acetate extracts of only A. sativum and $P$. emblica showed their synergistic activity with tetracycline, are displayed in table 2 .

In NKS70 strain, methanolic leaf extract of B. aristata had no antimicrobial activity alone, but enhances the activity of ciprofloxacin with an inhibition zone of $27 \pm 0.5$ and therefore, found to be a synergistic enhancer. Methanolic P. emblica extract measured inhibition zone of $28 \pm 0.7$ with ciprofloxacin, exhibited maximum synergistic activity. Among ethyl acetate extracts, combination effects of ciprofloxacin with P. emblica and A. sativum were $27.5 \pm 0.5$ and $27 \pm 0.5$ respectively, both exhibited maximum synergism. With the combined effect of tetracycline, the P. emblica methanolic extract produced inhibition zone of $24.3 \pm 0.8$ and $A$. sativum formed $19.5 \pm 0.5$ of inhibition zone, which revealed their maximum synergistic activities.

In NKS174 strain, a maximum zone of inhibition $33.6 \pm 0.9$ and $28.6 \pm 0.5$ were measured in the methanolic extract of $P$. emblica with ciprofloxacin and tetracycline respectively.

In NKS773 strain, the combined effect of ciprofloxacin with $P$. emblica formed inhibition zone of $26.5 \pm 0.6$ and A. sativum measured $24 \pm 0.1$, both exhibited best synergistic activities. Inhibition zone measured for $P$. emblica with tetracycline was $20.6 \pm 0.4$.

On the basis of synergistic activities of Allium sativum, Syzygium aromaticum, Berberis aristata, Rhus cotinus and Phyllanthus emblica, methanolic extracts revealing maximum synergism were further selected for evaluation of their phytochemicals and efflux pump inhibitory activity.

Results obtained for the qualitative screening of phytochemicals are presented in table 3 . The results revealed the presence of medically active compounds in the five plants studied. From this table, it is evident that alkaloids, phenols, terpenoids, flavonoids, reducing sugars and saponins were present in almost all the plants. Flavonoids were absent only in the fruit of $P$. emblica. Terpenoids and reducing sugars were present in all plant extracts. Saponins and phenols were present in all except $A$. sativum. Alkaloids were absent in the S. aromaticum, A. sativum and also in R. cotinus.

Berberine works as an efflux pump substrate and inhibits the growth of bacteria in the presence of an EPI. The experimental approach to detect EPI activity was to test the combined action of a plant extract with $30 \mu \mathrm{g} / \mathrm{ml}$ or $89 \mu \mathrm{M}$ berberine added at a subinhibitory concentration. Extracts that inhibited cell growth in the presence of berberine and had no activity when added alone were likely to contain an EPI. Inhibition of cell growth in the presence of berberine exhibited by extracts was in the following order: $P$. emblica (M) $>$ A. sativum $(\mathrm{M})>$ S. aromaticum $(\mathrm{M})>R$. cotinus $(\mathrm{M})>B$. aristata $(\mathrm{M})$ (Fig.1). Therefore, methanolic extract of $P$. emblica was found to be an active efflux pump inhibitor as it increases the efficacy of berberine.

Table 1: Medicinal plants possessing synergistic activity with ciprofloxacin

\begin{tabular}{|c|c|c|c|c|c|c|c|c|}
\hline \multirow{3}{*}{$\begin{array}{l}\text { S. } \\
\text { No. }\end{array}$} & \multirow{3}{*}{$\begin{array}{l}\text { Plant name } \\
\text { (voucher } \\
\text { specimen no.)* }\end{array}$} & \multicolumn{4}{|c|}{ Methanolic extracts } & \multicolumn{3}{|c|}{ Ethyl acetate extracts } \\
\hline & & & $\begin{array}{l}\text { S70 } \\
\text { dtype }\end{array}$ & $\begin{array}{l}\text { NKS174 } \\
\text { knockout }\end{array}$ & $\begin{array}{l}\text { NKS773 over } \\
\text { expressive }\end{array}$ & $\begin{array}{l}\text { NKS70 } \\
\text { wildtype }\end{array}$ & $\begin{array}{l}\text { NKS174 } \\
\text { knockout }\end{array}$ & $\begin{array}{l}\text { NKS773 over } \\
\text { expressive }\end{array}$ \\
\hline & & \multicolumn{7}{|c|}{ Diameter of zone of inhibition (in $\mathrm{mm}$ ) } \\
\hline \multirow[t]{4}{*}{1} & S. aromaticum & $\mathrm{PE}$ & $12 \pm 0.0$ & $13 \pm 0.0$ & $13 \pm 0.0$ & $10 \pm 0.0$ & $10 \pm 0.0$ & $10 \pm 0.0$ \\
\hline & (flower buds) & $\mathrm{PE}+\mathrm{A}$ & $20 \pm 0.5$ & $25 \pm 0.5$ & $18 \pm 0.5$ & $18 \pm 0.1$ & $23 \pm 0.5$ & $12 \pm 0.4$ \\
\hline & (SUBMS/BOT- & A & $16 \pm 0.0$ & $20 \pm 0.4$ & $12 \pm 0.4$ & $16 \pm 0.5$ & $20 \pm 0.4$ & $12 \pm 0.4$ \\
\hline & S219) * & DMSO & - & - & - & - & - & - \\
\hline \multirow[t]{4}{*}{2} & A. sativum (Bulbs) & $\mathrm{PE}$ & $12 \pm 0.0$ & $13 \pm 0.0$ & $12 \pm 0.0$ & $12 \pm 0.0$ & $11 \pm 0.0$ & $11 \pm 0.0$ \\
\hline & (SUBMS/BOT- & $\mathrm{PE}+\mathrm{A}$ & $27.5 \pm 0.5$ & $30.5 \pm 0.4$ & $24 \pm 0.1$ & $27 \pm 0.5$ & $30 \pm 0.2$ & $22.5 \pm 0.3$ \\
\hline & S221)* & $\mathrm{A}$ & $23 \pm 0.1$ & $26 \pm 0.2$ & $18 \pm 0.1$ & $23 \pm 0.0$ & $26 \pm 0.0$ & $18 \pm 0.0$ \\
\hline & & DMSO & - & - & - & - & - & - \\
\hline \multirow[t]{4}{*}{3} & R. cotinus (leaf) & PE & $14.6 \pm 0.2$ & $16.6 \pm 0.4$ & $16 \pm 0.1$ & $13 \pm 0.2$ & $13 \pm 0.1$ & $14 \pm 0.1$ \\
\hline & (SUBMS/BOT- & $\mathrm{PE}+\mathrm{A}$ & $27.3 \pm 0.7$ & $30.3 \pm 0.8$ & $23.3 \pm 0.5$ & $26 \pm 0.5$ & $30 \pm 0.2$ & $19 \pm 0.1$ \\
\hline & S184)* & $\mathrm{A}$ & $23.6 \pm 0.4$ & $26 \pm 0.5$ & $18 \pm 0.1$ & $24 \pm 0.2$ & $28 \pm 0.5$ & $17 \pm 0.4$ \\
\hline & & DMSO & - & - & - & - & - & - \\
\hline \multirow[t]{4}{*}{4} & B. aristata (leaf) & $\mathrm{PE}$ & - & - & - & - & - & - \\
\hline & (SUBMS/BOT- & $\mathrm{PE}+\mathrm{A}$ & $27 \pm 0.5$ & $32.5 \pm 0.4$ & $25 \pm 0.3$ & $25 \pm 0.2$ & $29 \pm 0.3$ & $21.5 \pm 0.5$ \\
\hline & $\mathrm{S} 108)^{*}$ & A & $23 \pm 0.2$ & $28 \pm 0.1$ & $21 \pm 0.1$ & $24.5 \pm 0.3$ & $28 \pm 0.1$ & $20 \pm 0.2$ \\
\hline & & DMSO & - & - & - & - & - & - \\
\hline \multirow[t]{4}{*}{5} & P. emblica (fruits) & $\mathrm{PE}$ & $12 \pm 0.5$ & $14 \pm 0.8$ & $16 \pm 0.8$ & $14.6 \pm 0.6$ & $17 \pm 0.1$ & $14.5 \pm 0.5$ \\
\hline & (SUBMS/BOT- & $\mathrm{PE}+\mathrm{A}$ & $28 \pm 0.7$ & $33.6 \pm 0.9$ & $26.5 \pm 0.6$ & $27.5 \pm 0.5$ & $32 \pm 0.6$ & $24.5 \pm 0.4$ \\
\hline & S170) * & $\mathrm{A}$ & $23 \pm 0.5$ & $28 \pm 0.5$ & $20.5 \pm 0.1$ & $23.5 \pm 0.3$ & $28 \pm 0.5$ & $20.5 \pm 0.1$ \\
\hline & & DMSO & - & - & - & - & - & - \\
\hline
\end{tabular}

A = Antibiotic $(5 \mu \mathrm{g} / \mathrm{ml})$, DMSO = Dimethyl sulfoxide, $\mathrm{PE}=$ Plant extract, $(-)=$ No inhibition zone $(\mathrm{n}=3$, Values are represented as mean \pm SD). 
Table 2: Medicinal plants possessing synergistic activity with tetracycline

\begin{tabular}{|c|c|c|c|c|c|c|c|c|}
\hline \multirow{3}{*}{$\begin{array}{l}\text { S. } \\
\text { No. }\end{array}$} & \multirow{3}{*}{$\begin{array}{l}\text { Plant name } \\
\text { (voucher specimen no.)* }\end{array}$} & \multicolumn{4}{|c|}{ Methanolic extracts } & \multicolumn{3}{|c|}{ Ethyl acetate extracts } \\
\hline & & $\begin{array}{l}\text { NKS70 } \\
\text { wildtype }\end{array}$ & NKS174 & ockout & $\begin{array}{l}\text { NKS773 over } \\
\text { expressive }\end{array}$ & $\begin{array}{l}\text { NKS70 } \\
\text { wildtype }\end{array}$ & $\begin{array}{l}\text { NKS174 } \\
\text { knockout }\end{array}$ & $\begin{array}{l}\text { NKS773 over } \\
\text { expressive }\end{array}$ \\
\hline & & \multicolumn{7}{|c|}{ Diameter of zone of Inhibition (mm) } \\
\hline \multirow[t]{4}{*}{1} & S. aromaticum (flower & PE & $12 \pm 0.0$ & $13 \pm 0.0$ & $13 \pm 0.0$ & $10 \pm 0.0$ & $10 \pm 0.0$ & $10 \pm 0.0$ \\
\hline & buds) (SUBMS/BOT-S219) * & $\mathrm{PE}+\mathrm{A}$ & $19 \pm 0.5$ & $23 \pm 0.0$ & $22 \pm 0.1$ & $17.5 \pm 0.1$ & $20 \pm 0.5$ & $16 \pm 0.0$ \\
\hline & & A & $15 \pm 0.1$ & $17.5 \pm 0.5$ & $11 \pm 0.0$ & $15 \pm 0.1$ & $17.5 \pm 0.5$ & $11 \pm 0.0$ \\
\hline & & DMSO & - & - & - & - & - & - \\
\hline \multirow[t]{4}{*}{2} & A. sativum (bulbs) & PE & $12 \pm 0.0$ & $13 \pm 0.0$ & $12 \pm 0.0$ & $12 \pm 0.0$ & $11 \pm 0.0$ & $11 \pm 0.0$ \\
\hline & (SUBMS/BOT-S221) * & $\mathrm{PE}+\mathrm{A}$ & $19.5 \pm 0.5$ & $23.5 \pm 0.5$ & $16 \pm 0.0$ & $18 \pm 0.6$ & $22 \pm 0.6$ & $17 \pm 0.8$ \\
\hline & & $\mathrm{A}$ & $14.5 \pm 0.5$ & $18.5 \pm 0.4$ & $11 \pm 0.0$ & $14 \pm 0.2$ & $18 \pm 0.4$ & $12 \pm 0.5$ \\
\hline & & DMSO & - & - & - & - & - & - \\
\hline \multirow[t]{4}{*}{3} & R. cotinus (leaf) & $\mathrm{PE}$ & $14.6 \pm 0.2$ & $16.6 \pm 0.4$ & $16 \pm 0.1$ & $13 \pm 0.2$ & $13 \pm 0.1$ & $14 \pm 0.1$ \\
\hline & (SUBMS/BOT-S184) * & $\mathrm{PE}+\mathrm{A}$ & $16.5 \pm 0.3$ & $27 \pm 0.5$ & $14.5 \pm 0.5$ & $15 \pm 0.5$ & $20 \pm 0.2$ & $15 \pm 0.1$ \\
\hline & & $\mathrm{A}$ & $12.5 \pm 0.4$ & $22.5 \pm 0.5$ & $10 \pm 0.1$ & $13.3 \pm 0.2$ & $22.5 \pm 0.5$ & $10 \pm 0.4$ \\
\hline & & DMSO & - & - & - & - & - & - \\
\hline \multirow[t]{4}{*}{4} & B. aristata (leaf) & PE & - & - & - & - & - & - \\
\hline & (SUBMS/BOT-S108) * & $\mathrm{PE}+\mathrm{A}$ & $14.9 \pm 0.2$ & $26 \pm 0.5$ & $14 \pm 0.5$ & $13 \pm 0.5$ & $17 \pm 0.2$ & $10 \pm 0.1$ \\
\hline & & A & $11 \pm 0.1$ & $22 \pm 0.5$ & $10 \pm 0.4$ & $13.3 \pm 0.2$ & $18.6 \pm 0.5$ & $10 \pm 0.4$ \\
\hline & & DMSO & - & - & - & - & - & - \\
\hline \multirow[t]{4}{*}{5} & P. emblica (fruits) & $\mathrm{PE}$ & $12 \pm 0.5$ & $14 \pm 0.8$ & $17 \pm 0.8$ & $14.6 \pm 0.6$ & $17 \pm 0.1$ & $14.5 \pm 0.5$ \\
\hline & (SUBMS/BOT-S170) * & $\mathrm{PE}+\mathrm{A}$ & $24.3 \pm 0.8$ & $28.6 \pm 0.5$ & $20.6 \pm 0.4$ & $19.5 \pm 0.9$ & $27.6 \pm 0.6$ & $18.6 \pm 0.1$ \\
\hline & & A & $19.0 \pm 0.6$ & $23.6 \pm 0.4$ & $14.6 \pm 0.4$ & $15 \pm 0.1$ & $23.3 \pm 0.6$ & $14.1 \pm 0.2$ \\
\hline & & DMSO & - & - & - & - & - & - \\
\hline
\end{tabular}

$\mathrm{A}=$ Antibiotic $(15 \mu \mathrm{g} / \mathrm{ml}), \mathrm{DMSO}=$ Dimethyl sulfoxide, $\mathrm{PE}=$ Plant extract, $(-)=$ No inhibition zone $(\mathrm{n}=3$, Values are represented as mean $\pm \mathrm{SD})$.

Table 3: Preliminary phytochemical screening of the extracts possessing synergistic activity with used antibiotics

\begin{tabular}{|c|c|c|c|c|c|c|}
\hline S. No. & Name of compounds & S. aromaticum & A. sativum & R. cotinus & B. aristata & P. emblica \\
\hline 1 & Flavonoids (Alkaline reagent test) & + & + & + & + & - \\
\hline 2 & Alkaloids (Wagner's reagent) & - & - & - & + & + \\
\hline 3 & Reducing sugars (Fehling test) & + & + & + & + & + \\
\hline 4 & Saponins (Foam test) & + & - & + & + & + \\
\hline 5 & Terpenoids (Salkowki's test) & + & + & + & + & + \\
\hline 6 & Phenols & + & - & + & + & + \\
\hline
\end{tabular}

Legend: $(+)=$ present, $(-)=$ Absent

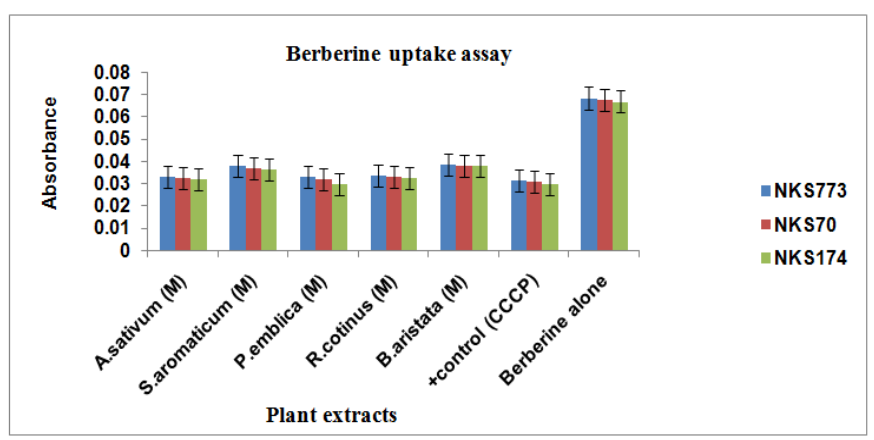

Fig. 1: Absorbance shown by plant extracts at $89 \mu \mathrm{M}$ berberine

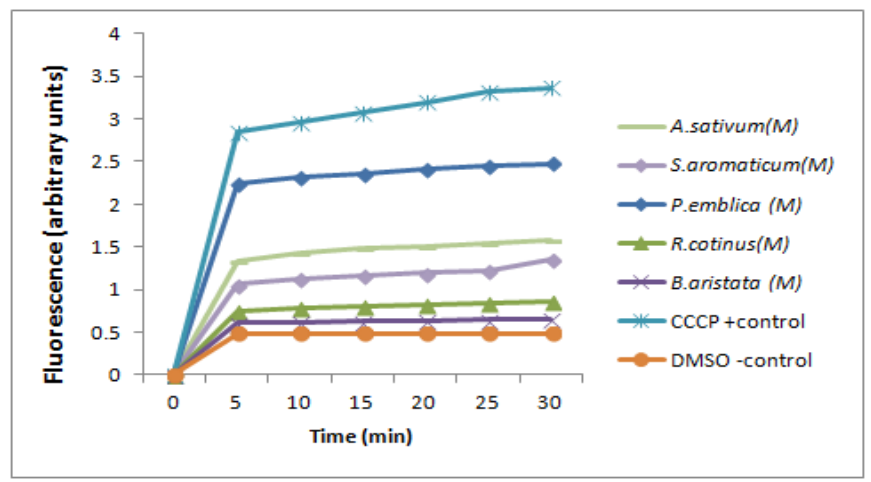

Fig. 2: Effect of plant extracts on the accumulation of $100 \mu \mathrm{M}$ ethidium bromide by knockout strain (NKS174) 


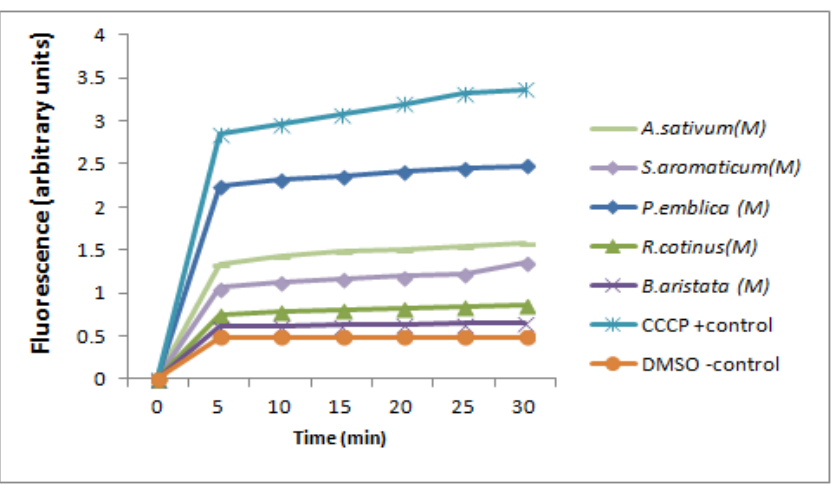

Fig. 3: Effect of plant extracts on the accumulation of $100 \mu \mathrm{M}$ ethidium bromide by wild type (NKS70) strain

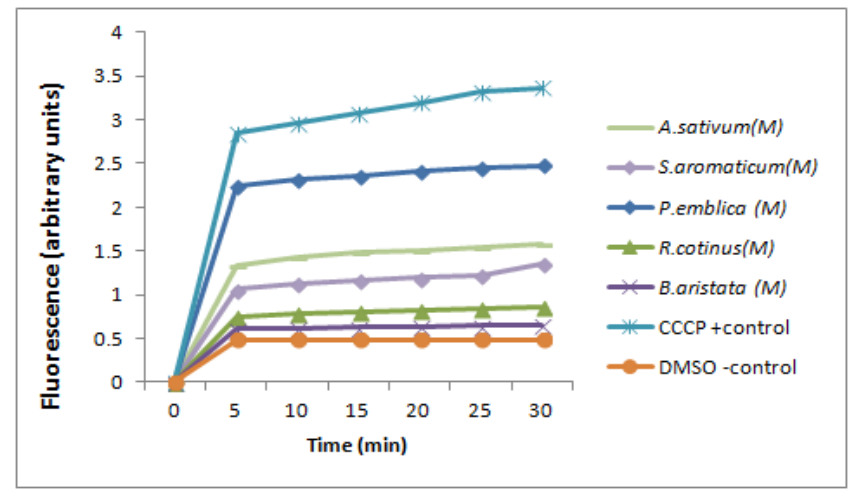

Fig. 4: Effect of plant extracts on the accumulation of $100 \mu \mathrm{M}$ ethidium bromide by over expressive (NKS773) strain.

Figs 2, 3 and 4 showed the effect of plant extracts on the level of accumulation of ethidium bromide $(100 \mu \mathrm{M})$ in the NKS174 knockout, NKS70 wild type and NKS773 over expressive strains respectively. Hence, berberine and $\mathrm{EtBr}$ at $89 \mu \mathrm{M}$ and $100 \mu \mathrm{M}$ respectively, act as a marker for the detection of EPI in plant extracts. Berberine uptake assay and ethidium bromide inhibition assay were performed for all five synergistic plant extracts against $S$. Typhimurium strains. Hence, observations of berberine assay and EtBr assay were found similar and resulted in maximum EPI activity in the methanolic extract of $P$. emblica.

\section{DISCUSSION}

Multidrug efflux pumps are the major mechanism of drug resistance in Salmonella. Most effective multidrug efflux pump is AcrAB, exporting various drugs, dyes, and detergents. The EPI evaluation assay studies suggest that some moderate or strong polar components play a role in inhibiting bacteria. The approach to the detection of molecules that can interfere with the process of efflux to enhance the activity of existing antibiotics helps in tackling with antibiotic resistance and explore genomic-driven new lead molecules [32].

The present study was done with an aim to find plant extracts that may be combined with antibiotics to produce effects greater than their individual effect and act as efflux pump inhibitors. Synergism from natural sources has received much attention and efforts have been put in to identify compounds by phytochemical screening that can act as efflux pump inhibitors. The ability of the compounds to reverse antibiotic resistance conferred by the expression of the AcrAB-TolC efflux pump was determined. Salmonella enterica serovar Typhimurium is resistant to fluoroquinolones, chloramphenicol-florfenicol, and tetracycline due to the presence of the AcrAB-TolC efflux pump [33]. Drug synergism between known antibiotics and bioactive plant extracts is a novel concept and could be beneficial (synergistic or additive interaction) or deleterious (antagonistic).
Our potentiation study revealed that plants, namely, Allium sativum, Syzygium aromaticum, Berberis aristata, Rhus cotinus and Phyllanthus emblica synergistically increased the antimicrobial activity of ciprofloxacin and tetracycline. Our results were consistent with previous in vitro studies reported that crude extracts of Indian medicinal plants, Acorus calamus, Hemidesmus indicus, Holarrhena antidysenterica and Plumbago zeylanica showed their synergism with tetracycline and ciprofloxacin against an extended spectrum of beta-lactamase, producing multidrug-resistant enteric bacteria in which ciprofloxacin showed more synergy with the extracts than tetracycline [34-40]. Plants either contain antimicrobials that act synergistically with antibiotics or possess compounds that have no intrinsic antibacterial activity, but are able to sensitize the pathogen to a previously ineffective antibiotic [37].

Our secondary metabolite studies of above five medicinal plants have shown the presence of flavonoids, saponins, alkaloid, terpenoid, reducing sugars and phenols which are of great importance in the field of drug research. All the five medicinal plants selected for screening were found to possess terpenoids and reducing sugars. Phenols are also present in all plant extracts except A. sativum. The phenolic compounds are one of the largest and most ubiquitous groups of plant metabolites [41]. A literature search revealed that they possess biological properties such as antiapoptosis, anti-aging, anticarcinogen, antiinflammation and improvement of endothelial function, as well as inhibition of angiogenesis and cell proliferation activities [42]. Alcoholic and aqueous Heartwood extracts of medicinal plant Berberis aristata, containing berberine alkaloid also known to be a potent antiinflammatory agent [43]. The plant extracts revealed the presence of saponins, which are known to produce an inhibitory effect on inflammation [44]. Moreover, alkaloids have been associated with medicinal uses for centuries and are one of the diverse groups of secondary metabolites found to have antimicrobial activity by inhibiting DNA topoisomerase. Terpenoids are also known to possess antimicrobial, antifungal, antiparasitic, antiviral, 
antihyperglycemic, anti-inflammatory and immune-modulatory properties $[45,46]$.

A fluorimetric study was employed to assess the fluorescence or accumulation of berberine and ethidium bromide, a substrate of the efflux pump. The fluorescence of ethidium bromide is maximal inside cells; thereby the accumulation was evidenced by an increase in the fluorescence units. The addition of the methanolic P. emblica showed slightly lesser accumulation of ethidium bromide in the cells than in the presence of CCCP. However, the accumulation was significantly higher than that of the control without any EPI, in all three strains. However, it was evident that $P$. emblica play a major role in AcrAB efflux pump inhibition, therefore, act as an efflux pump inhibitor. One of the previous study of Piddock et al. [47] observed the efflux pump inhibitors of the AcrAB efflux pump from Theobroma cacao and Catha edulis sources. Therefore, efflux pump inhibitors (EPIs) are promising therapeutic agents, as they restore the standard antibiotic activity. Co-administration of EPIs with antibiotics that act as pump substrates could increase drug levels intracellularly and therefore renew the efficacy of existing antibacterial agents.

\section{CONCLUSION}

In conclusion, the present study probably suggests the possibility of concurrent use of these antimicrobial agents and extracts in combination in treating infections caused by $S$. Typhimurium strains and helps in the reuse of these antibiotics into clinical. Methanolic extract of $P$. emblica found to be a potent inhibitor of the AcrABmediated efflux of ethidium bromide and berberine. Though, $P$. emblica has shown EPI activity in bacteria, as per our knowledge, there is no report on EPI activity of $P$. emblica in AcrAB-efflux systems. As the incidence of drug-resistant $S$. Typhimurium is increasing at an alarming rate, a combination therapy of antibiotics with these phytochemicals would be a better approach to combating the multidrug resistance. This will eventually help in better treatment outcome and help in decreasing the mortality rate of patients with infections caused by the MDR pathogens. A better understanding of plant-derived bioactive compounds, EPI of substantial medicinal merit may be fundamental to the development of pharmacological agents and may lead to the improved application of existing plant-derived CAM therapies.

\section{ACKNOWLEDGMENT}

We are thankful to Kunihiko Nishino, Associate professor of Osaka University (Japan) for providing strains.

\section{CONFLICT OF INTERESTS}

The authors have no conflict of interest to report

\section{REFERENCES}

1. Scherer CA, Miller SI. Molecular pathogenesis of salmonellae. In: Principles of Bacterial Pathogenesis; 2001. p. 266-333.

2. Coates A, Hu Y, Bax R, Page C. The future challenges facing the development of new antimicrobial drugs. Nat Rev Drug Discovery 2002;1:895-910.

3. Lomovskaya 0, Bostian KA. Practical applications and feasibility of efflux pump inhibitors in the clinic a vision for applied use. Biochem Pharmacol 2006;71:910-8.

4. Abreu AC, McBain AJ, Simoes M. Plants as sources of new antimicrobials and resistance-modifying agents. Nat Prod Rep 2012;29:1007-21.

5. Kourtesi C, Ball AR, Huang YY, Jachak SM, Vera DM, Khondkar P, et al. Microbial efflux systems and inhibitors: approaches to drug discovery and the challenge of clinical implementation. Open Microbiol J 2013;7:34-52.

6. Ruggerone P, Murakami S, Pos KM, Vargiu AV. RND efflux pumps structural information translated into function and inhibition mechanisms. Curr Top Med Chem 2013;13:3079-100.

7. Braga LC, Leite AA, Xavier KG, Takahashi JA, Bemquerer MP, Chartone-Souza E, et al. Synergic interaction between pomegranate extracts and antibiotics against Staphylococcus aureus. Can J Microbiol 2005;51:541-7.
8. Tyagi R, Sharma G, Jasuja ND, Menghani E. Indian medicinal plants as an effective antimicrobial agent. J Crit Rev 2016;3:69-71.

9. Uma B. Phytochemical analysis and antimicrobial activity of clitorea ternatea linn against extended-spectrum betalactamase producing enteric and urinary pathogens. Asian J Pharm Clin Res 2009;2:94-6.

10. Tegos GP, Haynes M, Strouse JJ, Khan MM, Bologa CG, Oprea TI, et al. Microbial efflux inhibition; tactics and strategies. Curr Pharm Des 2011;17:1291-302.

11. Gibbons S. Phytochemicals for bacterial resistance--strengths, weaknesses, and opportunities. Planta Med 2008;74:594-602.

12. Edeoga HO, Okwu DE, Mbaebie BO. Phytochemical constituents of some Nigerian medicinal plants. Afr J Biotechnol 2005;4:685-8.

13. Mann J. Secondary Metabolism. Oxford University Press: London; 1978. p. 154.

14. Lewis K, Ausubel FM. Prospects of plant derived antibacterials. Nat Biotechnol 2006;24:1504-7.

15. Bambeke FV, Balzi E, Tulkens PM. Antibiotic efflux pumps. Biochem Pharmacol 2000;60:457-70.

16. Brenwald NP, Gill MJ, Wise R. Prevalence of a putative efflux mechanism among fluoroquinolone-resistant clinical isolates of streptococcus pneumonia. Antimicrob Agents Chemother 1998;42:2032-5.

17. Saidijam M, Benedetti G, Ren Q, Xu Z, Hoyle CJ, Palmer SL, et al. Microbial drug efflux proteins of the major facilitator superfamily. Curr Drug Targets 2006;7:793-811.

18. Tegos G, Stermitz FR, Lomovskaya O, Lewis K. Multidrug pump inhibitors uncover remarkable activity of plant antimicrobials. Antimicrob Agents Chemother 2002;46:3133-41.

19. Yin Y, He X, Szewczyk P, Nguyen T, Chang G. Structure of the multidrug transporter EmrD from Escherichia coli. Science 2006;312:741-4.

20. Piddock LJV. Clinically relevant chromosomally encoded multidrug resistance efflux pumps in bacteria. Clin Microbiol Rev 2006;9:382-402.

21. Aneja KR, Joshi R, Sharma C. Potency of Barleria prionitis L. bark extracts against oral diseases causing strains of bacteria and fungi of clinical origin. New York Sci J 2010;3:512.

22. National Committee for Clinical Laboratory Standards (NCCLS). Performance standards for antimicrobial disk and dilution susceptibility tests for bacteria isolated from animals. NCCLS; 1991. p. M31-A.

23. National Committee for Clinical Laboratory Standards (NCCLS). Methods for antimicrobial susceptibility testing of anaerobic bacteria. NCCLS; 1993. p. M11-A3.

24. Sofowara A. Medicinal plants and traditional medicine in Africa. Spectrum Books Ltd. Ibadan: Nigeria; 1993. p. 289-300.

25. Chanda SV, Parekh J, Karathia N. Evaluation of antibacterial activity and phytochemical analysis of Bauhinia variegate $\mathrm{L}$. bark. Afr J Biomed Res 2006;9:53-6.

26. Parekh J, Chanda SV. In vitro antimicrobial activity and phytochemical analysis of some Indian medicinal plants. Turk J Biol 2007;31:53-8.

27. Kumar GS, Jayaveera KN, Kumar CKA, Sanjay UP, Swamy BMV Antimicrobial effects of Indian medicinal plants against acneinducing bacteria. Trop J Pharm Res 2007;6:717-23.

28. Onwukaeme DN, Ikuegbvweha TB, Asonye CC. Evaluation of phytochemical constituents, antibacterial activities, and effect of exudates of Pycanthus angolensis Weld Warb (Myristicaceae) on corneal ulcers in rabbits. Trop J Pharm Res 2007;6:725-30.

29. Harborne JB. Phytochemical methods: a guide to modern techniques of plant analysis. Chapman and hall Ltd., London: UK; 1973. p. 49-188.

30. Belofsky G, Carreno R, Lewis K, Ball A, Casadei G, Tegos GP. Metabolites of the "smoke tree", Dalea spinosa, potentiate antibiotic activity against multidrug-resistant Staphylococcus aureus. J Nat Prod 2006;69:261-4.

31. Zechini B, Versace I. Inhibitors of multidrug resistant efflux systems in bacteria. Recent Pat Antiinfect Drug Discovery 2009;4:37-50.

32. Usha PTA, Jose S, Nisha AR. Antimicrobial drug resistance a global concern. Vet World 2010;3:138-9. 
33. Baucheron S, Tyler S, Boyd D, Mulvey MR, Chaslus-Dancla E, Cloeckaert A. AcrAB-TolC directs efflux-mediated multidrug resistance in Salmonella enterica Serovar Typhimurium DT104. Antimicrob Agents Chemother 2004;48:3729-35.

34. Ahmad I, Aqil F. In vitro efficacy of bioactive extracts of 15 medicinal plants against ES $\beta$ L-producing multidrug-resistant enteric bacteria. Microbiol Res 2007;162:264-75.

35. Aiyegoro OA, Afolayan AJ, Okoh AI. Synergistic interaction of Helichrysum pedunculatum leaf extracts with antibiotics against wound infection associated bacteria. Biol Res 2009;42:327-38.

36. Sibanda T, Okoh AI. In vitro evaluation of the interactions between acetone extracts of Garcinia kola seeds and some antibiotics. Afr J Biotech 2008;7:1672-8.

37. Betoni JE, Mantovani RP, Barbosa LN, Di Stasi LC, Fernandes JA. Synergism between plant extract and antimicrobial drugs used on Staphylococcus aureus diseases. Mem Inst Oswaldo Cruz 2006;101:387-90.

38. Darwish R, Aburjai T, Al-Khalil S, Mahafzah A. Screening of antibiotic resistant inhibitors from local plant materials against two different strains of Staphylococcus aureus. J Ethnopharmacol 2002;79:359-64.

39. Isogai E, Isogai H, Hirose K, Hayashi S, Oguma K. In vivo synergy between green tea extract and levofloxacin against Enterohemorrhagic Escherichia coli 0157 infection. Curr Microbiol 2001;42:248-51.

40. Aiyegoro OA, Afolayan AJ, Okoh AI. In vitro time-kill assessment of crude methanol extract of Helichrysum pedunculatum leaves. Afr J Biotechnol 2008b; 7:1684-8.
41. Singh R, Singh SK, Arora S. Evaluation of antioxidant potential of ethyl acetate extract/fractions of acacia auriculiformis a. Cunn Food Chem Toxicol 2007:45:1216-23.

42. Han X, Shen T, Lou H. Dietary polyphenols and their biological significance. Int J Mol Sci 2007;950-88.

43. Singh V, Gunjan, Katiyar D. Anti-inflammatory activity of alcoholic and aqueous heartwood extracts of Berberis aristata DC. Asian J Pharm Clin Res 2014;7 Suppl 1:210.

44. Just MJ, Recio MC, Giner RM, Cueller MU, Manez S, Billia AR, et al. the anti-inflammatory activity of unusual lupine saponins from bupleurum fruticescens. Planta Med 1998;64:404-7.

45. Rabi T, Bishayee A. Terpenoids and breast cancer chemoprevention. Breast Cancer Res Treat 2009;115:223-39.

46. Wagner $\mathrm{KH}$, Elmadfa I. Biological relevance of terpenoids: Overview is focusing on mono-di and tetraterpenes. Ann Nutr Metab 2003;47:95-106.

47. Piddock LJV, Garvey MI, Rahman MM, Gibbons S. Natural and synthetic compounds such as trimethoprim behave as inhibitors of efflux in Gram-negative bacteria. J Antimicrob Chemother 2010;65:1215-23.

\section{How to cite this article}

- Jyoti Mehta, Savita Jandaik, Urmila. Evaluation of phytochemicals and synergistic interaction between plant extracts and antibiotics for efflux pump inhibitory activity against Salmonella typhimurium strains. Int J Pharm Pharm Sci 2016;8(10):217-223. 